\title{
Treatment of Advanced/Metastatic Melanoma in the United States and Western Europe: Results of the CancerMPact Survey
}

This article was published in the following Dove Press journal: Cancer Management and Research

\section{Stephanie Hawthorne \\ Linda Zhao \\ Madelyn Hanson \\ Gena Kanas \\ Christine Davis \\ David Robinson (D) \\ Matthew Turnure (D) \\ Otavio Clark (D)}

Kantar, Health Division, New York, NY, USA

Correspondence: Otavio Clark

Kantar, 175 Greenwich St, WTC 3, 35th

Floor, New York, NY 10007, USA

Email otavio.clark@kantar.com
Context: Melanoma treatment has substantially changed over the last several years, yet little information regarding physician's preferences around treatment exists.

Objective: Our aim is to describe the results of the CancerMPact (CMP) survey performed in 2019 about the treatment of advanced/metastatic melanoma.

Methods: CMP is a data source from Kantar, Health Division, containing data on cancer epidemiology and treatment. Once a year, Kantar performs a series of surveys with specialists in the field of interest in the United States of America (USA), Western Europe (WE), Japan, and China. The results of the survey reported in this work comprise the answers from 94 USA and 99 WE physicians about the treatment of melanoma.

Results: In the first-line for the BRAF wild-type population, immuno-oncology (IO) drugs including nivolumab, ipilimumab or pembrolizumab (alone or in combination) were used in $80.1 \%$ of the cases in the USA and $70.6 \%$ in WE. Conventional chemotherapy or cytokinebased treatments were used in $16.4 \%$ of the USA patients and $28.2 \%$ in WE. In the secondline in the USA, $45.8 \%$ of BRAF wild-type patients received IO drugs, while $45.0 \%$ of patients received conventional chemotherapy or cytokine-based treatments. The majority of patients with BRAF mutant advanced/metastatic melanoma were treated in the first-line with BRAF-targeted therapy (61.3\% USA, $71.9 \% \mathrm{WE})$, and few patients received conventional chemotherapy or cytokine-based treatments $(11.9 \%$ USA, $12.4 \% \mathrm{WE})$; the most commonly used BRAF-targeted therapy was the combination of dabrafenib plus trametinib. In the second-line, BRAF mutant patients received IO drugs (45.1\% USA, 53.7\% WE), targeted therapy $(37.6 \%$ USA, $32 \% \mathrm{WE})$ or conventional chemotherapy/cytokine-based treatments (14.4\% USA, $11.7 \%$ WE).

Conclusion: The use of IO or targeted therapy for patients with advanced/metastatic melanoma is the preferred treatment strategy by physicians in the USA and WE based on BRAF mutation status. Many patients still receive conventional chemotherapies or cytokines with unsubstantial benefit, especially in recurrent patients of BRAF wild type.

Keywords: melanoma, immunotherapy, chemotherapy, variations in practice, survey

\section{Introduction}

Melanoma is a malignant tumor that develops from melanocytes and can arise in many different types of body tissues, most commonly originating in the skin. Melanoma is the rarest of the skin cancers, yet the most lethal. ${ }^{1}$ Curative surgical treatment is possible for tumors in early stages (Stage I-IIIa), but patients with 
more advanced disease are not considered curable with currently available treatments. ${ }^{1,2}$

Prior to 2010, no systemic therapy had been shown to significantly improve overall survival (OS) for patients with advanced or metastatic melanoma based on results from randomized clinical trials. ${ }^{3}$ Dacarbazine, approved by the FDA in the 1970s, had been the only approved drug for the systemic treatment of advanced melanoma. However, the outcomes after use of dacarbazine had been disappointing, with treated patients having less than 5\% overall 5-year survival. ${ }^{1}$ Other systemic treatments, including the combination of conventional chemotherapy with cytokines (interferon and interleukin), have not been shown to extend the OS of patients with advanced or metastatic melanoma, either in the first- or second-line. ${ }^{1,4}$

Beginning in 2011, many different drugs including targeted therapy and immuno-oncology drugs (IO) began to enter the market for melanoma. In 2011, the Food and Drug Administration (FDA) approved vemurafenib, a targeted therapy for the treatment of melanoma patients that harbor the BRAF V600F mutation. ${ }^{5}$ In 2013, dabrafenib targeted therapy was approved for the same indication. MEK inhibitors arrived at the market in 2013 with the approval of trametinib, followed by cobimetinib in 2015. ${ }^{5}$ While clinical studies showed that BRAF and MEK inhibitors improved clinical response, progressionfree survival, and the overall survival of melanoma patients with these mutations, these benefits were further increased when patients were treated with a combination of the two mechanisms of action. ${ }^{1,6,7}$ The IO drugs, mainly checkpoint inhibitors, entered the US market starting with ipilimumab in 2011, followed by nivolumab and pembrolizumab for the treatment of advanced/metastatic melanoma patients. ${ }^{1,5,6}$ Other drugs have since been approved or are currently being studied in clinical trials. IO drugs have improved the OS for melanoma patients and offer a long-term survival for approximately $25 \%$ to $30 \%$ of cases. ${ }^{1,5-7}$ The high number of approved drugs for the treatment of melanoma in the past decade has brought increased complexity to the clinical decisionmaking process, yet limited information is available regarding physician preferences on how to treat the disease. $^{8}$

Our aim in this publication is to report the results of a proprietary survey of physicians that treat advanced/ metastatic melanoma patients in the USA and WE, conducted in 2019, to better understand their current treatment practices in light of the changing market landscape.

\section{Methods}

CancerMPact $^{\circledR}$ (CMP) is a proprietary database from Kantar, Health Division, containing data on cancer epidemiology and treatments. ${ }^{9}$ Once a year the company performs a series of surveys with specialists in the field of interest in the USA, Western Europe (Italy, France, Germany, Spain and the United Kingdom), Japan, and China. In 2019, CMP comprised a total of 4906 physicians from these countries that answered questions for 31 different tumor types, with the USA and WE physicians comprising $72 \%(n=3515)$ of the total global survey respondents.

The CMP melanoma study recruited 94 USA and 99 WE (Italy, France, Germany, Spain and the United Kingdom) physicians to participate in the online survey. To take part in the survey, physicians must have been a board-certified (or the equivalent in the European countries) medical and/or hematologic oncologist, dermatologist, or dermatology oncologist; must have been in practice between 3 and 30 years; and must have treated a minimum of 8 melanoma patients per month.

To develop the questionnaire, an internal Kantar team of oncology experts studied the patterns of care reported in international guidelines, such as the National Comprehensive Cancer Network (NCCN), as well as approvals for new drugs by the US Food and Drug Association (FDA) and the European Medicines Agency (EMA). The team also reviewed pivotal trial data that is published in peer-reviewed medical journals and major oncology conferences, looking for current practices and potential changes in melanoma treatment.

The questionnaire asked physicians about their profile (years in practice, practice type, practice specialty, patient volume, etc.) and about how, in the last six months, they had treated their patients with melanoma. Questions were detailed to cover aspects of treatment for all stages of the disease and relevant biomarkers in advanced or metastatic melanoma (BRAF mutations and PD-L1 overexpression). The survey included questions about the modality of treatment used (radiation, surgery, systemic therapy, etc.), the systemic therapy regimens used for each clinical situation, and the duration of each systemic therapy administered. Physicians were explicitly asked to report only how they actually treated their patients.

The online questionnaire was programmed, fielded, and hosted by another company (Lightspeed) and the anonymized raw data were securely transferred to the Kantar 
Health Division team, which conducted the data analysis and tabulation. No formal statistical treatment was given to the results and data were reported as an unweighted average of all responses.

In this paper, we report data from the survey conducted specifically for melanoma patient treatment in the USA and WE, which was fielded in January 2019.

\section{Results}

The 94 USA surveyed physicians reported seeing 34.1 patients per month, on average. These physicians reported an average of 17.6 years in practice after medical residence and the most common places of work were in an oncology group practice (20.6\%), followed by $14.6 \%$ in an academic medical center. In WE, the 99 surveyed doctors reported seeing an average of 49.4 patients per month. They had an average of 16.4 years of practice after residence and the most commonplace of work was at academic medical center $(44.1 \%)$, followed by a cancer center affiliated to a hospital (14.7\%). Details about the surveyed population are reported in Table 1 .

Among the biomarkers, BRAF mutation testing was the most commonly ordered for metastatic melanoma patients by physicians in both regions (73.3\% WE, $77.1 \%$ USA), followed by PD-L1 (45.6\% WE, 57.7\% USA) and KIT (42.3\% WE, 37.7\% USA). Other biomarkers were reported to have been ordered for less than $3 \%$ of the patients.

Table I Characteristics of Physicians Surveyed

\begin{tabular}{|l|l|l|}
\hline & USA - N/\% & WE - N/\% \\
\hline $\begin{array}{l}\text { Number of physicians surveyed } \\
\text { Average number of years of practice } \\
\text { after residency (range) }\end{array}$ & 94 & 99 \\
$\begin{array}{l}\text { Average number of melanoma } \\
\text { patients treated by each physician } \\
\text { monthly (range) }\end{array}$ & 34.1 (8-200) & $49.4(9-300)$ \\
\hline $\begin{array}{l}\text { Practice settings } \\
\text { Oncology group practice } \\
\text { Cancer center, affiliated with }\end{array}$ & 20.6 & \\
a hospital & 6.5 & 14.7 \\
$\begin{array}{l}\text { Private practice } \\
\text { Academic medical center }\end{array}$ & 48 & \\
Hospital, affiliated with a medical & 3.8 & 7.1 \\
school & 34.6 & 44.1 \\
Hospital, general & 3.2 & 10.5 \\
Cancer center, independent & 3.2 & 4.1 \\
\hline
\end{tabular}

Abbreviations: USA, United States of America; WE, Western Europe.
Table 2 shows the first-line systemic treatments used in WE and the USA, stratified by BRAF mutation status. IO drugs were by far the preferred treatment for the metastatic melanoma patient with wild-type BRAF. USA physicians reported treating $80.1 \%$ of their wild-type BRAF patients with IO drugs, either as monotherapy or in combination. Of the IO treatments, the combination of nivolumab and ipilimumab was used in $30.9 \%$ of the cases, followed by monotherapy with nivolumab $(26.9 \%)$ and pembrolizumab $(13.5 \%)$. For the BRAF wild-type patient population in WE, physicians reported the use of IO therapy for $70.6 \%$ of the patients, including nivolumab (20.6\%) and pembrolizumab (19\%) monotherapy, followed by the combination of nivolumab and ipilimumab (18.3\%) as the most used regimens. USA physicians reported the use of conventional chemotherapy or other immunotherapy drugs in several regimens for $16.4 \%$ of this population, while WE physicians reported using these treatment regimens for $28.2 \%$ of their patients.

For patients with BRAF mutant melanoma, physicians reported using BRAF-targeted therapy in $61.3 \%$ and $71.9 \%$ of the cases in the first-line setting in the USA and WE, respectively. The combination of dabrafenib with trametinib was the most commonly used treatment for this subpopulation (33.7\% USA, 36.2\% WE). The combination of cobimetinib and vemurafenib was the next most commonly used targeted therapy (14.2\% USA, $17.5 \% \mathrm{WE}$ ). An IO agent was used in $25.7 \%$ and $15.3 \%$ of the cases for this population with mutant BRAF in the USA and WE, respectively. Among the IO regimens, the combination of nivolumab and ipilimumab was the most commonly used (10.6\% USA, 5.3\% in WE). Regimens of conventional chemotherapy and cytokine-based treatments were used to treat $11.9 \%$ of patients in the USA and $12.4 \%$ of patients in WE.

In the second-line treatment (Table 3) for patients with BRAF wild type or unknown mutation, USA physicians' preferences were almost evenly divided between IO regimens $(45.8 \%)$ and conventional chemotherapy and cytokines (45.0\%), whereas WE physicians reported a higher preference for IO regimens over conventional chemotherapy and cytokine-based treatments ( $54.9 \%$ and $40.2 \%$, respectively).

For the second-line treatment for BRAF-mutated patients, USA physicians reported to have used IO drugs in $45.1 \%$ of their patients, targeted therapy in $37.6 \%$ and conventional chemotherapy in $14.4 \%$ of their patients; WE physicians used these treatments in $53.7 \%, 32.0 \%$ and $11.7 \%$ of their patients, respectively. 
Table 2 First-Line, Systemic Therapy Utilization and Number of Months by BRAF Status, Metastatic Melanoma, 2019

\begin{tabular}{|c|c|c|c|c|c|c|c|c|}
\hline \multirow[t]{3}{*}{ Regimen } & \multicolumn{4}{|l|}{ USA } & \multicolumn{4}{|l|}{ WE } \\
\hline & \multicolumn{2}{|c|}{$\begin{array}{l}\text { BRAF Wildtype or } \\
\text { Unknown }\end{array}$} & \multicolumn{2}{|c|}{ BRAF Mutant } & \multicolumn{2}{|c|}{$\begin{array}{l}\text { BRAF Wildtype or } \\
\text { Unknown }\end{array}$} & \multicolumn{2}{|c|}{ BRAF Mutant } \\
\hline & Utilization & $\begin{array}{l}\text { No. of } \\
\text { Months }\end{array}$ & Utilization & $\begin{array}{l}\text { No. of } \\
\text { Months }\end{array}$ & Utilization & $\begin{array}{l}\text { No. of } \\
\text { Months }\end{array}$ & Utilization & $\begin{array}{l}\text { No. of } \\
\text { Months }\end{array}$ \\
\hline $\begin{array}{l}\text { Conventional } \\
\text { chemotherapy/cytokines } \\
\text { Cisplatin, dacarbazine, } \\
\text { carmustine, IL-2\%, IFNa }^{\&} \\
\text { Sorafenib, carboplatin, } \\
\text { paclitaxel } \\
\text { CVD }^{\#} \\
\text { Dacarbazine } \\
\text { Dacarbazine, interferon } \\
\text { Other chemotherapy } \\
\text { Total CC/OI }\end{array}$ & $\begin{array}{l}3.6 \% \\
* \\
* \\
* \\
* \\
12.8 \% \\
16.4 \%\end{array}$ & $\begin{array}{l}6.0 \\
- \\
- \\
- \\
-\end{array}$ & $\begin{array}{l}* \\
3.1 \% \\
* \\
* \\
* \\
8.8 \% \\
11.9 \%\end{array}$ & $\begin{array}{l}- \\
6.0 \\
- \\
- \\
-\end{array}$ & $\begin{array}{l}* \\
* \\
4.5 \% \\
6.3 \% \\
5.0 \% \\
12.3 \% \\
28.2 \%\end{array}$ & $\begin{array}{l}- \\
- \\
6.8 \\
6.3 \\
7.9\end{array}$ & $\begin{array}{l}* \\
* \\
3.0 \% \\
9.4 \% \\
12.4 \%\end{array}$ & $\begin{array}{l}- \\
- \\
8.8\end{array}$ \\
\hline $\begin{array}{l}\text { Target therapy } \\
\text { Cobimetinib, Vemurafenib } \\
\text { Dabrafenib, Trametinib } \\
\text { Vemurafenib } \\
\text { Encorafenib, Binimetinib } \\
\text { Trametinib } \\
\text { Dabrafenib } \\
\text { Total target }\end{array}$ & $\begin{array}{l}0.0 \% \\
0.0 \% \\
1.7 \% \\
0.0 \% \\
0.0 \% \\
0.0 \% \\
1.7 \%\end{array}$ & $\begin{array}{l}- \\
- \\
8.0 \\
- \\
- \\
-\end{array}$ & $\begin{array}{l}14.2 \% \\
33.7 \% \\
9.5 \% \\
3.8 \% \\
\\
61.3 \%\end{array}$ & $\begin{array}{l}9.3 \\
10.5 \\
7.2 \\
10.4 \\
\\
-\end{array}$ & $\begin{array}{l}0.0 \% \\
0.0 \% \\
0.0 \% \\
0.0 \% \\
0.0 \% \\
0.0 \% \\
0.0 \%\end{array}$ & $\begin{array}{l}- \\
- \\
- \\
- \\
-\end{array}$ & $\begin{array}{l}17.5 \% \\
36.2 \% \\
9.2 \% \\
1.4 \% \\
2.6 \% \\
4.9 \% \\
71.9 \%\end{array}$ & $\begin{array}{l}13.0 \\
12.8 \\
10.5 \\
11.3 \\
10.0 \\
10.2\end{array}$ \\
\hline $\begin{array}{l}\text { Immunotherapy } \\
\text { Ipilimumab, dacarbazine } \\
\text { Nivolumab, Ipilimumab } \\
\text { Ipilimumab } \\
\text { Nivolumab } \\
\text { Pembrolizumab } \\
\text { Total immunotherapy }\end{array}$ & $\begin{array}{l}0.9 \% \\
30.9 \% \\
7.9 \% \\
26.9 \% \\
13.5 \% \\
80.1 \%\end{array}$ & $\begin{array}{l}8.5 \\
10.8 \\
7.9 \\
10.8 \\
11.4\end{array}$ & $\begin{array}{l}1.4 \% \\
10.6 \% \\
3.4 \% \\
5.4 \% \\
4.9 \% \\
25.7 \%\end{array}$ & $\begin{array}{l}4.3 \\
10.3 \\
4.9 \\
9.9 \\
10.4\end{array}$ & $\begin{array}{l}3.0 \% \\
18.3 \% \\
9.7 \% \\
20.6 \% \\
19.0 \% \\
70.6 \%\end{array}$ & $\begin{array}{l}6.8 \\
9.8 \\
7.3 \\
13.2 \\
11.7\end{array}$ & $\begin{array}{l}0.4 \% \\
5.3 \% \\
2.3 \% \\
4.6 \% \\
2.6 \% \\
15.3 \%\end{array}$ & $\begin{array}{l}5.3 \\
10.0 \\
7.6 \\
13.0 \\
11.9\end{array}$ \\
\hline $\begin{array}{l}\text { Other } \\
\text { Talimogene laherparepvec } \\
\text { Investigational Drug (Clinical } \\
\text { Trial) } \\
\text { Total other }\end{array}$ & $\begin{array}{l}0.6 \% \\
1.3 \% \\
1.9 \%\end{array}$ & $\begin{array}{l}9.0 \\
-\end{array}$ & $\begin{array}{l}0.4 \% \\
0.8 \% \\
1.2 \%\end{array}$ & $\begin{array}{l}6.0 \\
-\end{array}$ & $\begin{array}{l}0.3 \% \\
0.9 \% \\
1.2 \%\end{array}$ & $\begin{array}{l}8.0 \\
-\end{array}$ & $\begin{array}{l}0.4 \% \\
0.1 \% \\
0.5 \%\end{array}$ & $\begin{array}{l}24.0 \\
-\end{array}$ \\
\hline
\end{tabular}

Notes: ${ }^{\$}$ Other chemotherapy includes many different schemes, with dacarbazine, interferon, interleukin, vinblastine, paclitaxel, carboplatin, alone in combined; excludes combinations with newer immunotherapies (pembrolizumab, nivolumab, ipilimumab etc) and targeted therapy. ${ }^{\#}$ CVD - cisplatin, vinblastine, dacarbazine. \% IL2 - Interleukin 2. ${ }^{\circledR} \mathrm{IFNa}$ - Interferon alpha. *less than $3 \%$.

Abbreviation: CC, conventional chemotherapy.

\section{Discussion}

Advanced melanoma is one of the tumors with the most improvements in treatment over the last several years, in particular when new immunotherapies and targeted therapies reached the market. The clinical landscape now includes new IO and targeted therapies that show significant improvements in OS compared to the older treatments. ${ }^{1,3}$ Around $30 \%$ of patients can achieve long- term survival with these new treatments. ${ }^{1,3,7}$ Overall, the results of this survey show that interviewed physicians are aligned with this fact, with IO or targeted therapies making up over $70 \%$ of the treatments prescribed by physicians as the first-line treatment for advanced melanoma patients, a remarkable evolution from five years ago. ${ }^{10}$

These new treatments (IO and targeted therapy) are well tolerated, but this benefit comes with what has been 
Table 3 Second-Line, Systemic Therapy Utilization and Number of Months by BRAF Status, Metastatic Melanoma, 2019

\begin{tabular}{|c|c|c|c|c|c|c|c|c|}
\hline \multirow[t]{3}{*}{ Regimen } & \multicolumn{4}{|l|}{ USA } & \multicolumn{4}{|l|}{ WE } \\
\hline & \multicolumn{2}{|c|}{$\begin{array}{l}\text { BRAF Wildtype or } \\
\text { Unknown }\end{array}$} & \multicolumn{2}{|c|}{ BRAF Mutant } & \multicolumn{2}{|c|}{$\begin{array}{l}\text { BRAF Wildtype or } \\
\text { Unknown }\end{array}$} & \multicolumn{2}{|c|}{ BRAF Mutant } \\
\hline & Utilization & $\begin{array}{l}\text { No. of } \\
\text { Months }\end{array}$ & Utilization & $\begin{array}{l}\text { No. of } \\
\text { Months }\end{array}$ & Utilization & $\begin{array}{l}\text { No. of } \\
\text { Months }\end{array}$ & Utilization & $\begin{array}{l}\text { No. of } \\
\text { Months }\end{array}$ \\
\hline \multicolumn{9}{|l|}{$\begin{array}{l}\text { Conventional } \\
\text { chemotherapy/cytokines }\end{array}$} \\
\hline $\begin{array}{l}\text { Sorafenib, carboplatin, } \\
\text { paclitaxel }\end{array}$ & $4.3 \%$ & 6.6 & $4.3 \%$ & 6.9 & $*$ & - & * & - \\
\hline Sorafenib, dacarbazine & $3.1 \%$ & 4.2 & $*$ & - & $*$ & & $*$ & - \\
\hline IFNa-2a $a^{\&}$ & $*$ & - & $*$ & - & $3.1 \%$ & 4.5 & * & - \\
\hline paclitaxel & $6.6 \%$ & 5.3 & $*$ & - & $3.4 \%$ & 8.5 & $*$ & - \\
\hline $\begin{array}{l}\text { cisplatin, dacarbazine, } \\
\text { carmustine, IL-2, IFNa }\end{array}$ & $*$ & - & $*$ & - & $4.2 \%$ & II.I & * & - \\
\hline $\mathrm{CVD}^{\#}$ & $*$ & - & $*$ & - & $3.5 \%$ & 8.3 & $*$ & - \\
\hline temozolomide & $17.4 \%$ & 5.5 & $*$ & - & $5.2 \%$ & 6.5 & * & - \\
\hline $\begin{array}{l}\text { dacarbazine, IFNa }{ }^{\&} \text {, } \\
\text { tamoxifen }\end{array}$ & $*$ & - & $*$ & - & $3.4 \%$ & 6.0 & * & - \\
\hline Dartmouth regimen & $8.2 \%$ & 6.5 & $5.4 \%$ & 6.6 & $*$ & - & $*$ & - \\
\hline dacarbazine & $*$ & - & $*$ & - & $8.7 \%$ & 6.9 & * & - \\
\hline Other chemotherapy ${ }^{\$}$ & $5.4 \%$ & - & $4.8 \%$ & - & $8.7 \%$ & - & $11.7 \%$ & - \\
\hline Total CC/OI & $45.0 \%$ & & $14.4 \%$ & & $40.2 \%$ & & $11.7 \%$ & \\
\hline \multicolumn{9}{|l|}{ Target therapy } \\
\hline Cobimetinib, Vemurafenib & $0.0 \%$ & - & $8.7 \%$ & 8.1 & $0.0 \%$ & - & $5.3 \%$ & 8.1 \\
\hline Dabrafenib, Trametinib & $0.0 \%$ & - & $19.6 \%$ & 7.9 & $0.0 \%$ & - & $11.0 \%$ & 10.5 \\
\hline Dabrafenib & $0.0 \%$ & - & $1.4 \%$ & 5.8 & $0.0 \%$ & - & $2.4 \%$ & 8.8 \\
\hline Encorafenib, Binimetinib & $0.0 \%$ & - & $5.5 \%$ & 7.9 & $0.0 \%$ & - & $3.1 \%$ & 9.7 \\
\hline Trametinib & $0.0 \%$ & - & $0.2 \%$ & 14.0 & $0.0 \%$ & - & $5.5 \%$ & 9.0 \\
\hline Vemurafenib & $0.0 \%$ & - & $2.1 \%$ & 9.0 & $0.0 \%$ & - & $4.7 \%$ & 8.1 \\
\hline Total target & $0.0 \%$ & & $37.6 \%$ & & $0 \%$ & & $32 \%$ & \\
\hline \multicolumn{9}{|l|}{ Immunotherapy } \\
\hline Ipilimumab, dacarbazine & $1.4 \%$ & 7.5 & $0.4 \%$ & 3.0 & $2.1 \%$ & 6.3 & $1.1 \%$ & 4.0 \\
\hline Nivolumab, Ipilimumab & $17.5 \%$ & 7.3 & $12.9 \%$ & 8.9 & $15.0 \%$ & 9.9 & $12.1 \%$ & 10.2 \\
\hline Ipilimumab & $10.8 \%$ & 6.3 & $5.1 \%$ & 5.8 & $13.4 \%$ & 8.0 & $7.2 \%$ & 6.9 \\
\hline Nivolumab & $5.5 \%$ & 8.4 & $14.6 \%$ & 7.1 & $12.8 \%$ & 9.3 & $18.9 \%$ & 12.0 \\
\hline Pembrolizumab & $10.6 \%$ & 8.1 & $12.2 \%$ & 7.8 & $11.5 \%$ & 10.5 & $14.4 \%$ & 10.1 \\
\hline Total immunotherapy & $45.8 \%$ & & $45.1 \%$ & & $54.9 \%$ & & $53.7 \%$ & \\
\hline \multicolumn{9}{|l|}{ Other } \\
\hline Talimogene laherparepvec & $4.3 \%$ & 5.2 & $0.2 \%$ & 4.0 & $1.0 \%$ & 10.0 & $0.5 \%$ & 9.7 \\
\hline $\begin{array}{l}\text { Investigational Drug (Clinical } \\
\text { Trial) }\end{array}$ & $4.8 \%$ & - & $2.7 \%$ & - & $4.0 \%$ & - & $2.1 \%$ & - \\
\hline Total other & $9.2 \%$ & & $2.9 \%$ & & $5.0 \%$ & & $2.6 \%$ & \\
\hline
\end{tabular}

Notes: ${ }^{\$}$ Other chemotherapy includes many different schemes, with dacarbazine, interferon, interleukin, vinblastine, paclitaxel, carboplatin, alone in combined; excludes combinations with newer immunotherapies (pembrolizumab, nivolumab, ipilimumab etc) and targeted therapy. ${ }^{\#}$ CVD - Cisplatin, vinblastine, dacarbazine. \% IL2 - Interleukin 2. ${ }^{\circledR} \mathrm{IFNa}$ - Interferon alpha. *less than 3\%. "\#artmouth regimen is a combination of chemotherapy with cytokines agents in high dose.

Abbreviation: CC, conventional chemotherapy.

called "financial toxicity." High treatment costs preclude equal access to these treatments for a portion of patients. ${ }^{11}$ One of the most intriguing finds of this survey is the relatively high percentage of patients that still receive conventional chemotherapy and cytokine-based treatment, despite the new IO and targeted therapies which have 
clearly showed superiority over these older agents. ${ }^{7}$ In the first-line treatment for BRAF wild type, a little over one quarter of patients in WE are still treated with these older regimens with limited survival benefit; in the USA, one in six melanoma patients receives this treatment. Also remarkable is the frequent use of conventional chemotherapy and cytokine-based treatment in the second-line setting in the BRAF wild-type population, with over $40 \%$ of patients receiving these treatments, which may demonstrate a lack of effective, acceptable treatments for this population.

There was a smaller variation for the BRAF-mutated population. In the first-line, over $60 \%$ of the patients received BRAF-targeted therapy in the USA as well as in WE. In the second-line, a smaller percentage of patients received conventional chemotherapy and cytokine-based treatment (less than 15\%). However, an increased percentage of patients received a newer $\mathrm{IO}$ regimen in the second-line in both the USA and WE (45.1\% and $53.7 \%$, respectively) compared to the first-line setting (25.7\% and $15.3 \%$, respectively).

There are a few limitations to this analysis: a potential for recall bias; however, we limited the answers to the last 6 months, what may diminish the bias; the fact that the physicians are reporting on their own patients which may or may not reflect the general melanoma patient population, and that we did not investigate survival post treatment or reasons why physicians made their choices.

\section{Conclusion}

The results of this survey show that the use of new IO or targeted therapy for patients with advanced/metastatic melanoma is the preferred treatment strategy by physicians in the USA and WE. However, a large percentage of patients still receive conventional chemotherapy and/or cytokine-based treatments with unsubstantial benefit, especially in the BRAF wild-type population in the second-line setting, which represents significant unmet medical needs for recurrent or refractory melanoma patients.

\section{Abbreviations}

CMP, CancerMPact; FDA, Food and Drug Administration; IO, immuno-oncology; NCCN, National Comprehensive Cancer Network; NSCLC, non-small-cell lung cancer; USA, United States of America; WE, Western Europe.

\section{Ethical Analysis}

The database used for this research, named CancerMPact, does not collect or use patient-level data, or any data involving people, medical records or human samples. All information is retrieved from online physician surveys regarding factual information around overall treatment patterns in Advanced/Metastatic Melanoma in the United States and Western Europe. Therefore, no Institutional Review Board approval was necessary.

\section{Acknowledgments}

Authors Would like to very much thank the whole CancerMPact team that made this work possible: Anna Boudoures, Kelly Clapp, Megan Epperson, Christina Fish, Qi Fu, Michael Gaschler, Sarthak Jain, Leonard Kusdra, Bhavna Murali, Knar Nersesyan, Sara Omlid, Stephanie Ritz, Katherine Stockstill, Cathy Su. The abstract of this paper was presented at the VIRTUAL 2020 ISPOR CONFERENCE as an abstract with interim findings. The abstract was published in the Abstracts of Virtual ISPOR 2020 in Value in Health Volume 23, Supplement 1, S1-S398 [https://www.valueinhealthjour nal.com/article/S1098-3015(20)32035-0/fulltext].

\section{Funding}

Kantar, Health Division.

\section{Disclosure}

Otavio Clark is a partner of Kantar Health Brazil, a consultancy company that produces Health Technology Assessment work for pharmaceutical companies. He has also acted as an advisory board member of different pharmaceutical companies.

All authors are employed by Kantar, a global consultancy company that acts in the healthcare market, and have as clients: pharmaceutical companies, health insurance companies and hospitals. The authors report no other conflicts of interest in this work.

\section{References}

1. Domingues B, Lopes JM, Soares P, Populo H. Melanoma treatment in review. ImmunoTargets Ther. 2018;7:35-49. doi:10.2147/ITT.S134842

2. National Comprehensive Cancer Network (NCCN). NCCN guidelines version 3.2019 cutaneous melanoma; 2019 [cited Sep 28, 2019]. Available from: https://www.nccn.org/professionals/physician_gls/ pdf/cutaneous_melanoma.pdf.

3. Rogiers A, Boekhout A, Schwarze JK, Awada G, Blank CU, Neyns B. Long-term survival, quality of life, and psychosocial outcomes in advanced melanoma patients treated with immune checkpoint inhibitors. J Oncol. 2019;2019:5269062. doi:10.1155/2019/5269062 
4. Sasse AD, Sasse EC, Clark LG, Ulloa L, Clark OA. Chemoimmunotherapy versus chemotherapy for metastatic malignan melanoma. Cochrane Database Syst Rev. 2007(1):Cd005413.

5. National Cancer Institute. Drugs approved for melanoma: national cancer institute; 2019. Available from: https://www.cancer.gov/aboutcancer/treatment/drugs/melanoma. Accessed July 3, 2020.

6. Marzagalli M, Ebelt ND, Manuel ER. Unraveling the crosstalk between melanoma and immune cells in the tumor microenvironment. Semin Cancer Biol. 2019;59:236-250. doi:10.10 16/j.semcancer.2019.08.002

7. Luke JJ. Comprehensive clinical trial data summation for BRAF-MEK inhibition and checkpoint immunotherapy in metastatic melanoma. Oncologist. 2019;24(11):e1197-e211. doi:10.1634/theoncologist.2018-0876

8. Ascierto PA, Bastholt L, Ferrucci PF, et al. The impact of patient characteristics and disease-specific factors on first-line treatment decisions for BRAF-mutated melanoma: results from a European expert panel study. Melanoma Res. 2018;28(4):333-340. doi:10.109 7/CMR.0000000000000455
9. Kantar Health. CancerMpact fact sheet. Kantar Health; 2018. Available from: https://www.kantarhealth.com/docs/datasheets/Kantar_Health_ CancerMPact_datasheet\%20.pdf. Accessed July 3, 2020.

10. Jones C, Zhao Z, Barber B, Bagijn M, Corrie P, Saltman D. Treatment patterns in advanced melanoma: findings from a survey of European oncologists. Eur J Cancer Care (Engl). 2015;24 (6):862-866. doi:10.1111/ecc. 12326

11. Kandolf Sekulovic L, Guo J, Agarwala S, et al. Access to innovative medicines for metastatic melanoma worldwide: melanoma world society and European association of dermato-oncology survey in 34 countries. Eur J Cancer. 2018;104:201-209. doi:10.1016/j.ejca.2018.09.013

\section{Publish your work in this journal}

Cancer Management and Research is an international, peer-reviewed open access journal focusing on cancer research and the optimal use of preventative and integrated treatment interventions to achieve improved outcomes, enhanced survival and quality of life for the cancer patient.
The manuscript management system is completely online and includes a very quick and fair peer-review system, which is all easy to use. Visit http://www.dovepress.com/testimonials.php to read real quotes from published authors. 